\title{
Development of an intervention to support the implementation of evidence-based strategies for optimising antibiotic prescribing in general practice
}

Aleksandra J. Borek ${ }^{1 *}$ D, Anne Campbell², Elle Dent ${ }^{1}$, Michael Moore ${ }^{3}$, Christopher C. Butler ${ }^{1}$, Alison Holmes ${ }^{2}$, A. Sarah Walker ${ }^{4,5,6}$, Monsey McLeod ${ }^{2,7,8+}$, Sarah Tonkin-Crine ${ }^{1 \dagger}$ and on behalf of the STEP-UP study team

\begin{abstract}
Background: Trials show that antimicrobial stewardship (AMS) strategies, including communication skills training, point-of-care C-reactive protein testing (POC-CRPT) and delayed prescriptions, help optimise antibiotic prescribing and use in primary care. However, the use of these strategies in general practice is limited and inconsistent. We aimed to develop an intervention to enhance uptake and implementation of these strategies in primary care.

Methods: We drew on the Person-Based Approach to develop an implementation intervention in two stages. (1) Planning and design: We defined the problem in behavioural terms drawing on existing literature and conducting primary qualitative research (nine focus groups) in high-prescribing general practices. We identified 'guiding principles' with intervention objectives and key features and developed logic models representing intended mechanisms of action. (2) Developing the intervention: We created prototype intervention materials and discussed and refined these with input from 13 health professionals and 14 citizens in two sets of design workshops. We further refined the intervention materials following think-aloud interviews with 22 health professionals.

Results: Focus groups highlighted uncertainties about how strategies could be used. Health professionals in the workshops suggested having practice champions, brief summaries of each AMS strategy and evidence supporting the AMS strategies, and they and citizens gave examples of helpful communication strategies/phrases. Think-aloud interviews helped clarify and shorten the text and user journey of the intervention materials. The intervention comprised components to support practice-level implementation: antibiotic champions, practice meetings with slides provided, and an 'implementation support' website section, and components to support individual-level uptake: website sections on each AMS strategy (with evidence, instructions, links to electronic resources) and material resources (patient leaflets, POC-CRPT equipment, clinician handouts).
\end{abstract}

\footnotetext{
* Correspondence: Aleksandra.borek@phc.ox.ac.uk

${ }^{\dagger}$ Monsey McLeod and Sarah Tonkin-Crine are joint authors of this study. ${ }^{1}$ Nuffield Department of Primary Care Health Sciences, University of Oxford, Radcliffe Observatory Quarter, Woodstock Road, Oxford OX2 6GG, UK

Full list of author information is available at the end of the article
}

(c) The Author(s). 2021 Open Access This article is licensed under a Creative Commons Attribution 4.0 International License, which permits use, sharing, adaptation, distribution and reproduction in any medium or format, as long as you give appropriate credit to the original author(s) and the source, provide a link to the Creative Commons licence, and indicate if changes were made. The images or other third party material in this article are included in the article's Creative Commons licence, unless indicated otherwise in a credit line to the material. If material is not included in the article's Creative Commons licence and your intended use is not permitted by statutory regulation or exceeds the permitted use, you will need to obtain permission directly from the copyright holder. To view a copy of this licence, visit http://creativecommons.org/licenses/by/4.0/ The Creative Commons Public Domain Dedication waiver (http://creativecommons.org/publicdomain/zero/1.0/) applies to the data made available in this article, unless otherwise stated in a credit line to the data. 
Conclusions: We used a systematic, user-focussed process of developing a behavioural intervention, illustrating how it can be used in an implementation context. This resulted in a multicomponent intervention to facilitate practice-wide implementation of evidence-based strategies which now requires implementing and evaluating. Focusing on supporting the uptake and implementation of evidence-based strategies to optimise antibiotic use in general practice is critical to further support appropriate antibiotic use and mitigate antimicrobial resistance.

Keywords: Implementation, Behaviour change, Qualitative, Antibiotic prescribing, Antimicrobial stewardship, Antibiotic resistance, Point-of-care C-reactive protein test, Delayed prescriptions, Communication, Intervention development

\section{Contributions to the literature}

- This paper reports a systematic process to developing digital behavioural interventions, drawing on the Person-Based Approach and combining theoretical modelling with qualitative research with target users.

- It illustrates the use of this approach in an implementation context and the value of involving target users at all stages of intervention development and planning implementation.

- It shows that professionals valued a brief, multicomponent implementation intervention with online training, physical resources, champions and practice meetings.

- This study adds knowledge on how to develop implementation interventions for clinical settings and how to best engage clinicians as the target users.

\section{Background}

Antimicrobial resistance (AMR) poses a severe global threat to public health and modern medicine. Without effective antimicrobial medicines, many common infections and routine medical and dental procedures will become life-threatening. One of the main contributing factors to AMR is over-use of antibiotics, especially in primary care where most antibiotics are prescribed [1]. Many antimicrobial stewardship (AMS) strategies have been used to optimise antibiotic prescribing and reduce antibiotic use, especially for acute respiratory infections in primary care [2-4]. Some have been implemented nationally or regionally in England as part of the Quality Premium incentive scheme, e.g. antibiotic prescribing targets; monitoring, feedback and benchmarking of antibiotic prescribing rates; and audit and feedback to individual prescribers by prescribing advisors from Clinical Commissioning Groups (CCGs) [1, 5-8]. Among many others, AMS strategies include using enhanced communication skills and patient leaflets, point-of-care Creactive protein testing (POC-CRPT) and delayed/backup antibiotic prescriptions (DPs). These strategies have been tested in clinical trials and systematic reviews of trials support their effectiveness in reducing antibiotic prescribing/use in primary care $[2,4,9]$.
The GRACE-INTRO trial [10-12], a large international study (including England and Wales), involved developing and testing two strategies to reduce antibiotic prescribing for lower respiratory tract infections: (i) online training for general practitioners (GPs) in enhanced communication skills, supported by interactive use of a patient booklet ('Caring for Coughs'), and (ii) using POC-CRPT. The $2 \times 2$ factorial trial tested each intervention alone, and both combined, against usual care. Participating practices were also asked to appoint a lead GP to organise a structured meeting on prescribing issues. The trial showed that both strategies were effective in reducing antibiotic prescriptions, with the combined arm showing the biggest effect [10]. At a 12month follow-up, the online communication skills training showed a longer-lasting effect [11]. Other trials in England have also shown interactive use of leaflets can help support communication when not prescribing antibiotics for children ('When Should I Worry' booklet [13]) and adults with respiratory infections (Infosheets [14]). UK-based trials also have shown that giving patients DPs (instead of immediate antibiotic prescriptions) with a good explanation is an effective strategy to safely reduce antibiotic use by patients: showing that only $33-39 \%$ of patients use antibiotics when given a DP and that the strategy helps prevent complications and reduce re-consultations and future consultations for similar illnesses [15-17].

While trials show that these three AMS strategies are safe and effective in reducing antibiotic prescriptions/ use, their uptake in the 'real world' in English general practices is unknown and, anecdotally, limited and inconsistent. The GRACE-INTRO training and booklet are currently not publically available, although similar ('STAR: Stemming the Tide of Antibiotic Resistance') communication training is $[18,19]$. The 'When Should I Worry' booklet is available online [20], but it is unclear how widely it is used. POC-CRPT is not routinely available in English general practices, except a few local pilots [21-23]. Finally, DPs are and can be used, but clinicians have varied views and approaches to DPs, many report not using DPs at all, and not coding them consistently [24-26]. Therefore, addressing this gap between trial evidence and real-world implementation of evidence-based AMS strategies is an important step 
following development and testing of interventions. It may be particularly important for those practices that remain high prescribers of antibiotics despite the availability of AMS strategies. These practices may require additional support to implement such strategies (e.g. the three aforementioned evidence-based but under-utilised AMS strategies) to help them optimise antibiotic prescriptions/use.

This study aimed to develop and evaluate an intervention to support the implementation (henceforth implementation intervention' or 'intervention') of three evidence-based AMS strategies (communication skills training and use of patient leaflets, POC-CRPT, and DPs) in high antibiotic prescribing general practices in England. It is a part of a larger research programme called STEPUP ('Improving the uptake and SusTainability of Effective interventions to promote Prudent antibiotic Use in Primary care') [27]. This paper describes the intervention development process and provides a comprehensive description of the implementation intervention.

\section{Methods and results}

\section{Overview of methods}

In our research, we drew on elements of the PersonBased Approach (PBA) [28-30] which is a systematic approach to developing behaviour change interventions, particularly those with digital components. It is distinctive from other approaches in its focus on involving people from the target user populations through qualitative research and co-design. The PBA helps integrate evidence and theory-based intervention development (focussing on psychosocial and behavioural change processes and techniques) with a user-centred design that improves the usability, acceptability and engagement of technology-based interventions. It has been used to develop a wide range of health-related behaviour change interventions to target patients and healthcare professionals [31], including the GRACE-INTRO intervention $[10,32]$ and a digital intervention to reduce antibiotic prescriptions in hospitals [33].

The main elements of the PBA are as follows: (i) undertaking qualitative research with people from the target user populations at all stages of intervention development (starting with exploring psychosocial and contextual influences on the target behaviour) and (ii) developing 'guiding principles' (comprising design objectives and key intervention features to achieve objectives) and theoretical integration that shows how the intervention will address the target behaviour and determinants. Table 1 summarises the steps taken in our intervention development. Progress through the steps was iterative so later steps fed back into earlier steps (e.g. feedback from design workshops influenced the theoretical modelling). In this paper, we describe the two stages of planning and developing the intervention; the implementation and evaluation of the intervention will be reported separately.

\section{Implementation intervention planning and design Step 1: Defining the problem, target behaviours, users and influences}

Methods In the initial part of the intervention development process, we drew on the expertise of the research team and existing literature and conducted primary qualitative research. The research team were a multidisciplinary group (GPs, a pharmacist, a psychologist, sociologists, statisticians and health economists and health

Table 1 Summary of the implementation intervention development process

\begin{tabular}{|c|c|c|}
\hline Stages & Steps & Person-Based Approach [28-30] \\
\hline $\begin{array}{l}\text { Planning \& design of } \\
\text { the intervention }\end{array}$ & $\begin{array}{l}\text { 1. Defining the problem in behavioural terms, identifying target } \\
\text { behaviours, users and influences on behaviour (literature scoping, } \\
\text { qualitative research, expert input) } \\
\text { 2. Creating guiding principles \& theoretical modelling (logic modelling) }\end{array}$ & $\begin{array}{l}\text { Intervention planning: } \\
\text { - Literature scoping and review } \\
\text { - Qualitative research with target users } \\
\text { - Formulating guiding principles (intervention } \\
\text { design objectives and key features of } \\
\text { intervention) } \\
\text { - Behavioural analysis and construction of logic } \\
\text { model }\end{array}$ \\
\hline $\begin{array}{l}\text { Developing the } \\
\text { intervention } \\
\text { (components) }\end{array}$ & $\begin{array}{l}\text { 3. Developing (drafting) intervention components \& materials (design } \\
\text { workshops) } \\
\text { 4. Refining intervention materials (think-aloud interviews) }\end{array}$ & $\begin{array}{l}\text { Intervention optimisation: } \\
\text { - Draft/refine intervention materials } \\
\text { - Qualitative piloting of draft materials } \\
\text { - Refine guiding principles } \\
\text { - Revisit behavioural analysis and refine logic } \\
\text { model }\end{array}$ \\
\hline $\begin{array}{l}\text { Implementing and } \\
\text { evaluating the } \\
\text { intervention }\end{array}$ & $\begin{array}{l}\text { 5. Implementing the intervention in real-life context } \\
\text { 6. Mixed-methods evaluation }\end{array}$ & $\begin{array}{l}\text { Mixed-methods process evaluation: } \\
\text { - Quantitative research } \\
\text { - Qualitative research with users } \\
\text { - Triangulation } \\
\text { - Examine theory-based questions drawn from } \\
\text { logic model }\end{array}$ \\
\hline
\end{tabular}


service researchers), including researchers experienced in optimising antibiotic prescribing in primary care. We used the team's expertise throughout the intervention development but especially in the initial planning.

As part of a related study [34,35], we conducted two scoping reviews of (i) studies of AMS strategies (interventions) and (ii) qualitative studies on influences on antibiotic prescribing; both included healthcare professionals in UK primary care and focussed on prescribing for acute respiratory infections. We used this evidence to identify evidence-based AMS strategies and modifiable influences on antibiotic prescribing.

Given that much existing qualitative research with healthcare professionals about AMS strategies was within trials and unspecific to implementation or highprescribing practices, we conducted our own qualitative research. The methods of this focus group study are reported in detail elsewhere [26]. In brief, we held nine focus groups with 50 professionals (3-11 per practice) in high-prescribing practices (i.e. top $20 \%$ for antibiotic prescribing based on 2017 PrescQIPP data [6]) in England to better understand practice professionals' views on antibiotic prescribing, optimisation and implementing/using POC-CRPT and DPs. The focus groups were conducted by AJB and AC using a semi-structured topic guide and lasted 49-87 min. Practices were reimbursed for participation. The data were analysed using an inductive thematic approach in NVivo software by four researchers (AJB, AC, STC, ED), and analytic saturation was achieved. The findings informed our choice of targeted influences and potential intervention components.

Results The problem and target behaviours: Drawing on the research team's expertise and experience, we identified the problem as low uptake and inconsistent use of evidence-based AMS strategies in English general practice. Thus, the target behaviour was use of evidencebased AMS strategies in general practice consultations for acute infections. We hypothesised that increased use of AMS strategies would decrease prescribing of (immediate) antibiotics. Using evidence from systematic reviews and clinical trials of AMS strategies in England, expertise of the research team, consideration of whether support already existed for an AMS strategy, and whether the support was within scope of and feasible in our study, we selected three AMS strategies: (i) communication skills training with interactive use of patient leaflets, (ii) POC-CRPT and (iii) DPs. For communication skills training and POC-CRPT, we aimed to support implementation of the training and resources developed and tested in the GRACE-INTRO study [10-12, 32]. For DPs, existing trials did not target clinician behaviour but rather aimed to assess the impact of DPs on patient behaviour (whether they used antibiotics when given a
DP), patient satisfaction, likelihood of re-consulting for the same or different illness and the safety of delaying antibiotics $[15,16]$; thus, we aimed to develop materials targeted at clinicians to promote DP use. Other effective AMS strategies exist that were not included [2-4], e.g. monitoring, feedback and benchmarking (peer comparison) of antibiotic prescribing rates, and audit and feedback to individual prescribers, have already been implemented in England [7, 8]; electronic clinical decision support tools/systems (which may involve different features and would require remote changes to and integration into different clinical systems software [14]) and patient education were considered unfeasible within and outside of scope of our study.

Target users: Although antibiotic prescribing in general practices has reduced in recent years, studies show that a proportion of general practices remain highprescribing [36-38]. Therefore, we identified the 'users' or 'population' to target by our intervention as healthcare professionals in high antibiotic prescribing practices (i.e. in the top quarter of antibiotic prescribing in England). We targeted prescribers and non-prescribers in these practices because communication skills (with leaflets) and POC-CRPT can be used by both prescribers and non-prescribers, whereas DPs are used by prescribers. However, we also envisaged that implementation of the strategies in practices may involve nonclinical practice professionals who support clinicians (e.g. receptionists triaging patients for POC-CRPT or managing DPs to be collected later). Therefore, we agreed that our intervention would target all general practice professionals, with a primary focus on prescribers.

Influences on antibiotic prescribing: We fully report the identified influences on antibiotic prescribing and optimisation in our review of qualitative studies in the UK [34, 35], our focus group study in high-prescribing practices [26] and in Supplementary File 1. From these, we selected influences considered important, modifiable by an intervention and most feasible to address. The iterative nature of the development process meant these targeted influences were further refined, particularly following the workshops (step 3). Table 2 shows which influences were targeted in the intervention and by which components. Supplementary File 2 reports the targeted influences matched with the Theoretical Domains Framework categories [39].

\section{Step 2: Creating guiding principles and theoretical modelling}

Methods After identifying target behaviours and influences, we established guiding principles for the intervention. These incorporated design objectives for the 
Table 2 Influences on antibiotic prescribing and optimisation

\begin{tabular}{|c|c|c|}
\hline Types of influences & $\begin{array}{l}\text { Influences on antibiotic prescribing \& optimisation } \\
\text { (identified and fully reported in }[26,34,35] \text { ) }\end{array}$ & Intervention components \\
\hline Evidence \& education & $\begin{array}{l}\text { 1. Clinician awareness of evidence \& guidelines } \\
\text { 2. Peer discussion \& learning } \\
\text { 3. Clinician training/education on antibiotic prescribing } \\
\text { 4. Advice from \& influence of relevant experts }\end{array}$ & $\begin{array}{l}\text { Website } \\
\text { Practice meetings, champion } \\
\text { Website } \\
\text { Website }\end{array}$ \\
\hline Clinical experience \& confidence & 5. Clinical experience \& confidence & Website, training \\
\hline Clinical assessment & $\begin{array}{l}\text { 6. Clinical uncertainty about illness aetiology, severity and/or } \\
\text { progression } \\
\text { 7. Additional diagnostic information from testing }\end{array}$ & $\begin{array}{l}\text { POC-CRPT } \\
\text { POC-CRPT }\end{array}$ \\
\hline $\begin{array}{l}\text { Perceptions of patient's expectations } \\
\& \text { satisfaction }\end{array}$ & $\begin{array}{l}\text { 8. Perceptions of patient expectations of antibiotics } \\
\text { 9. Preserving a good relationship with patient, patient } \\
\text { satisfaction \& avoiding conflict }\end{array}$ & $\begin{array}{l}3 \text { AMS strategies } \\
3 \text { AMS strategies }\end{array}$ \\
\hline Communication skills \& strategies & $\begin{array}{l}\text { 10. Ability to elicit \& manage patient's concerns \& expectations } \\
\text { 11. Ability to reassure \& safety-net } \\
\text { 12. Perceived importance of shared decision making } \\
\text { 13. Ability \& motivation to educate patients in consultations }\end{array}$ & $\begin{array}{l}\text { Comms } \\
3 \text { AMS strategies } \\
\text { Comms, DP } \\
\text { Website }\end{array}$ \\
\hline Time \& workload & $\begin{array}{l}\text { 14. Time pressure \& workload (e.g. wanting to save time \& } \\
\text { prevent future consultations) } \\
\text { 15. Consultation length ( } \& \text { not wanting to lengthen consultations) }\end{array}$ & $\begin{array}{l}\text { Website } \\
\text { Website }\end{array}$ \\
\hline Professional role \& ethos & 16. Perceptions of professional role \& ethos & Website, champion \\
\hline $\begin{array}{l}\text { Awareness \& perceptions of responsibility } \\
\text { for AMS }\end{array}$ & 17. Clinician awareness/knowledge of \& attitude to AMS & Champion \\
\hline Monitoring, feedback \& accountability & 18. Receiving feedback on prescribing & Practice meeting \\
\hline Perceptions of own \& others' prescribing & $\begin{array}{l}\text { 19. (In)Consistent approach to antibiotic prescribing between } \\
\text { clinicians/organisations }\end{array}$ & Practice meeting, champion \\
\hline Attitudes to \& use of AMS strategies* & $\begin{array}{l}\text { 20. Views on \& use of strategies } \\
\text { 21. Access to resources to use strategies }\end{array}$ & $\begin{array}{l}3 \text { AMS strategies } \\
3 \text { AMS strategies, resources }\end{array}$ \\
\hline $\begin{array}{l}\text { Additional influences identified in the } \\
\text { focus groups in relation to POC-CRPT } \\
\text { and DP [26] }\end{array}$ & $\begin{array}{l}\text { 22. Perceived fit of strategies with clinical roles and experience } \\
\text { 23. Perceived usefulness of strategies as social tools to negotiate } \\
\text { treatment and educate patients } \\
\text { 24. Ambiguities about strategies (incl. evidence, when and how } \\
\text { to use them, impact on antibiotic prescribing/use) } \\
\text { 25. Practice context (incl. ease of access, availability of } \\
\text { dispensary, deprivation, patient characteristics, time pressures, } \\
\text { costs, logistics/workflows) }\end{array}$ & $\begin{array}{l}\text { Website } \\
3 \text { AMS strategies } \\
\text { Website, practice meeting } \\
\text { Practice meeting, champions, } \\
\text { resources }\end{array}$ \\
\hline
\end{tabular}

Comms communication skills training (including interactive use of leaflets), DP delayed antibiotic prescriptions, POC-CRPT point-of-care C-reactive protein testing *Strategies identified in the qualitative studies (in usual care, outside of trials) included only DPs and leaflets, and not communication skills training or POC-CRPT; however, it can be assumed that similar influences are relevant to all three AMS strategies

intervention and its key features (i.e. how it would address these objectives).

We developed two logic models to illustrate the intended change mechanisms. The first described individual-level processes of how the AMS strategies facilitate change in clinicians' antibiotic prescribing behaviour. The second described practice-level processes of how the implementation intervention was intended to facilitate change in practice-wide implementation and clinicians' use of the AMS strategies. The logic models were refined throughout intervention development. We also identified formats by which to deliver the intervention (i.e. intervention components).

Results Table 3 summarises the guiding principles for the implementation intervention. We identified the importance of the intervention fitting the local context; thus, rather than developing a generic, prescriptive implementation plan, we aimed to support autonomy and tailoring by encouraging practices to develop their own implementation plan. The intervention provided professionals with a choice of AMS strategies to use, and how, by offering a range of resources, including multiple patient leaflets (printed and electronic), and two types of POC-CRPT equipment (qualitative and quantitative, which could be stored differently). The feedback from the design workshops (step 3) and think-aloud interviews (step 4) stressed the importance of intervention materials being concise and user-friendly, due to demands on professionals' time, and the importance of the intervention coming from a trustworthy source.

Our first logic model (Fig. 1) illustrates how the three AMS strategies are hypothesised to influence individuallevel change in antibiotic prescribing behaviour. We 
Table 3 Guiding principles for the implementation intervention

\begin{tabular}{|c|c|}
\hline Design objectives & Key features of the implementation intervention \\
\hline $\begin{array}{l}\text { To support practice-wide implementation and use of the AMS } \\
\text { strategies }\end{array}$ & $\begin{array}{l}\text { - Promote use of the three evidence-based AMS strategies in general practices } \\
\text { - Intervention features aimed at all practice professionals to support both } \\
\text { individual and practice-level change } \\
\text { - Support practices to develop and agree practice-wide, consistent approaches to } \\
\text { using the AMS strategies } \\
\text { - Nominate practice champions to provide peer encouragement and support }\end{array}$ \\
\hline $\begin{array}{l}\text { To support autonomy and enable tailoring in how the AMS } \\
\text { strategies are used }\end{array}$ & $\begin{array}{l}\text { - Offer a choice of leaflets and POC-CRPT equipment } \\
\text { - Non-prescriptive on how practices should implement strategies } \\
\text { - Non-prescriptive on how clinicians should use strategies } \\
\text { (including clinical situations) }\end{array}$ \\
\hline $\begin{array}{l}\text { To persuade users that information and AMS strategies are } \\
\text { evidence-based and trustworthy }\end{array}$ & $\begin{array}{l}\text { - Clear references to evidence and guidelines } \\
\text { - Endorsed by the President of the Royal College of General Practitioners } \\
\text { - Videos and testimonials of practising clinicians explaining how they use the } \\
\text { strategies } \\
\text { - Description of intervention as developed by a multidisciplinary university-based } \\
\text { team (including practising clinicians), with non-commercial research funding }\end{array}$ \\
\hline To be brief and concise & $\begin{array}{l}\text { - Website to take less than an hour to read } \\
\text { - Text as concise as possible } \\
\text { - Use of expandable boxes on the website with additional details } \\
\text { - Handouts for clinicians with key messages maximum of one A4 page }\end{array}$ \\
\hline To be easy to use and navigate & $\begin{array}{l}\text { - Similar structure of webpages for each strategy } \\
\text { - Access to all sections of the website from the navigation bar (no need to go } \\
\text { through the website sequentially, but sequential use possible) }\end{array}$ \\
\hline
\end{tabular}

identified the key target influences on antibiotic prescribing: clinicians' perceptions of patient expectations for antibiotics (influences 8 and 23, Table 2), addressed by all three AMS strategies; clinical uncertainty about indication for antibiotics and illness severity and progression (influence 6), addressed by POC-CRPT and DPs; concern that patients will (need to) re-consult (influence 14) and/or will be dissatisfied if not receiving something tangible (e.g. prescription, leaflet) (influence 9), addressed by communication strategies and DPs; and

\begin{tabular}{|c|c|c|c|c|}
\hline & $\begin{array}{l}\text { Influences on } \\
\text { antibiotic prescribing }\end{array}$ & $\begin{array}{l}\text { AMS strategies, } \\
\text { intervention components }\end{array}$ & Change in cognitions & Change in behaviours \\
\hline \multirow{5}{*}{ 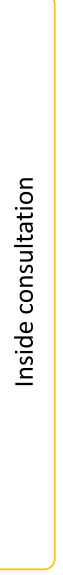 } & $\begin{array}{c}\text { Perceived patient } \\
\text { expectation for antibiotics } \\
\text { Clinical uncertainty whether }\end{array}$ & $\begin{array}{c}\text { Communication strategies } \\
\text { with interactive use of } \\
\text { patient leaflets, }\end{array}$ & $\begin{array}{l}\text { Increased motivation \& } \\
\text { self-efficacy to elicit \& } \\
\text { address patient } \\
\text { expectations \& concerns }\end{array}$ & $\begin{array}{l}\text { Follow communication } \\
\text { steps, supported by } \\
\text { leaflets }\end{array}$ \\
\hline & $\begin{array}{l}\text { Clinical uncertainty about } \\
\text { illness progression }\end{array}$ & $\begin{array}{c}\text { handout } \\
\text { Point-of-care CRP testing, }\end{array}$ & $\begin{array}{l}\text { Increased belief that AMS } \\
\text { strategies are acceptable } \\
\text { to patients }\end{array}$ & $\begin{array}{l}\text { Increased use of POC- } \\
\text { CRP testing to inform } \\
\text { treatment decisions }\end{array}$ \\
\hline & $\begin{array}{l}\text { Concern that patients will } \\
\text { (need to) re-consult }\end{array}$ & $\begin{array}{l}\text { Website, CRP testing } \\
\text { equipment, CRP training }\end{array}$ & $\begin{array}{l}\text { Decreased clinical } \\
\text { uncertainty }\end{array}$ & Increased use of delayed \\
\hline & $\begin{array}{l}\text { Concern about maintaining } \\
\text { patient satisfaction when not } \\
\text { giving something tangible }\end{array}$ & $\begin{array}{l}\text { Delayed antibiotic } \\
\text { prescriptions, }\end{array}$ & $\begin{array}{l}\text { Decreased concern about } \\
\text { complications when not } \\
\text { prescribing antibiotics }\end{array}$ & immediate antibiotics \\
\hline & $\begin{array}{c}\text { Concern that AMS strategies } \\
\text { take too long }\end{array}$ & Website, handout & $\begin{array}{l}\text { Increased belief that AMS } \\
\text { strategies will fit with } \\
\text { current workflows }\end{array}$ & $\begin{array}{l}\text { Decreased prescribing of } \\
\text { (immediate) antibiotics }\end{array}$ \\
\hline \multirow{2}{*}{ 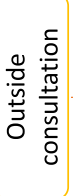 } & $\begin{array}{l}\text { Clinicians unaware of AMS } \\
\text { strategies \& evidence }\end{array}$ & $\begin{array}{l}\text { Website } \\
\text { Resources }\end{array}$ & & \\
\hline & $\begin{array}{l}\text { Clinicians unaware how } \\
\text { strategies differ from usual } \\
\text { practice }\end{array}$ & $\begin{array}{l}\text { ice antibiotic champion } \\
\text { Practice meeting }\end{array}$ & & \\
\hline
\end{tabular}


concern that the AMS strategies take too long or would lengthen consultations (influence 15), addressed by the information about communication strategies and DPs provided on the website as part of the intervention. Figure 1 shows these influences were addressed by the three AMS strategies directly and/or by the components of the implementation intervention and then were hypothesised to facilitate change in clinicians' cognitions, leading to higher uptake of the three AMS strategies and, consequently, decreased prescribing of (immediate) antibiotics.

The second logic model (Fig. 2) illustrates how the implementation intervention was hypothesised to facilitate the practice-level implementation of the three AMS strategies. In particular, we identified the lack of access to resources to enable use of these strategies (influence 21, Table 2) as a critical barrier, addressed by providing printed leaflets/booklets and POC-CRPT equipment. Competing priorities, with high workloads and insufficient time (influence 14), constituted also key barriers to prioritising antibiotic optimisation and implementation of new strategies in practices and were addressed by identifying practice antibiotic champions to lead AMS and support colleagues in using AMS strategies. Finally, perceived inconsistency between clinicians' antibiotic prescribing and use of AMS strategies (influence 19) was a barrier due to concern about patients' expectations for antibiotics, dissatisfaction or re-consultations if not prescribed antibiotics; this was addressed through the champion and practice meetings that aimed to ensure more consistent, practice-wide approach.
Implementation intervention development and refinement

Step 3: Developing intervention components and materials (design workshops)

Methods We conducted four workshops to discuss intervention components: two in March and two in June 2019, with one workshop with professionals and one with citizens (i.e. members of the public) at each timepoint. Workshops were in-person and lasted approximately $3 \mathrm{~h}$ each. Informed consent was taken from all participants at the start, and participants were reimbursed for participation. All workshops were audiorecorded and transcribed verbatim.

Health professionals included GPs, nurses and CCG professionals responsible for AMS in primary care. For the first workshop, we invited participants from our earlier focus-group study, through professional networks, and representatives from local CCGs. These invitations were sent by email. For the citizen workshop, we advertised through a website promoting opportunities for public involvement in NHS, public health and social care research (www.peopleinresearch.org). All attendees of the first workshops were invited to the second workshops and we sought new participants as needed.

The first professional workshop aimed to gather views and feedback on the three AMS strategies and implementation support. We facilitated discussions to allow participants to voice their views and experiences around key questions. The first citizens' workshop focused on 'talking about infections and antibiotics with your GP' and 'helping GPs discuss back-up/delayed prescriptions

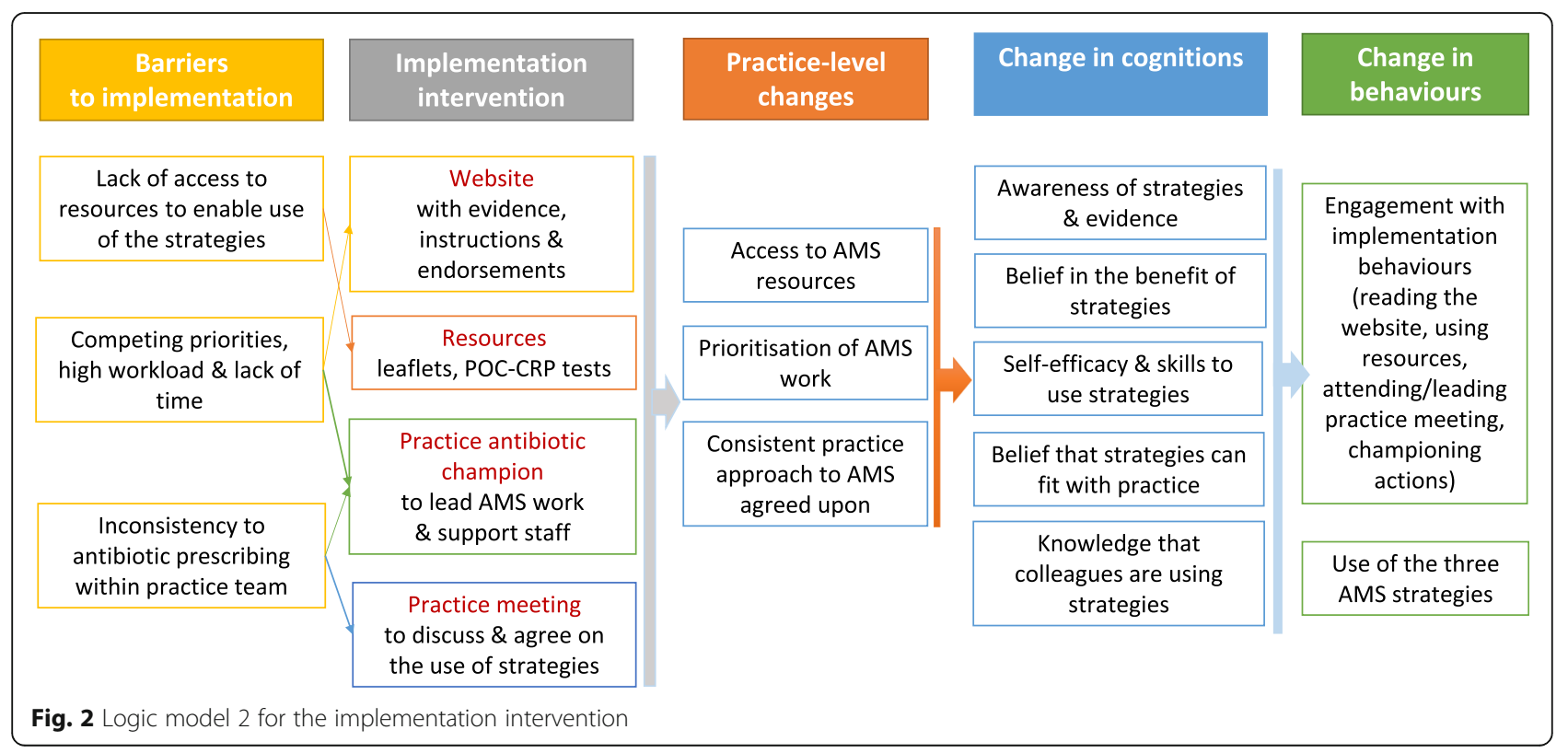


with patients'. We presented citizen participants with hypothetical scenarios (e.g. consulting a GP with a sore throat and a GP using certain communication strategies) to prompt discussions. Professionals and citizens were given handouts with the key questions and scenarios to enable them to add comments if they wished. Two researchers in each workshop made field notes.

After the first set of workshops, we combined field notes with data from the transcripts, participants' comments from the handouts, and relevant suggestions from the focus group study. All suggestions were summarised and discussed by the study team and used to develop draft implementation intervention materials. For the website, we developed a website design brief and worked with a professional web designer. We drafted content for the webpages and developed prototypes of the webpages and resources.

The second professionals' workshop aimed to discuss and collect feedback on the content, design and delivery of the intervention components. We presented draft webpages on the three AMS strategies and resources. The second citizens' workshop further explored discussing back-up/delayed prescriptions, as well as views/suggestions on helping other types of prescribers to discuss prescribing decisions, and on different types of patient leaflets. Following the second set of workshops, we compiled the comments and suggestions as before and agreed changes to be made.

Results The first set of workshops were attended by 11 professionals (five GPs, five CCG pharmacists/prescribing advisors, one practice nurse prescriber) and by 14 citizens. The second set of workshops were attended by nine professionals (five GPs, three CCG pharmacists/advisors, one nurse prescriber) and by 10 citizens.

Following the first set of workshops, we made decisions about the intervention components (e.g. website sections, having practice rather than CCG champions). We made changes to the content of the training on communication strategies and communication about DPs (e.g. included examples of helpful/unhelpful communication strategies) (see Table 4).

The second set of workshops led to further changes to the website and resources (Table 5). As a result of the discussions, we presented the three AMS strategies in a purposeful order: (1) communication skills and leaflets (most sustainable, universal and cheapest); (2) POCCRPT (potentially helping to reduce inappropriate prescriptions but more costly and time-consuming); and (3) DP (helping to reduce immediate antibiotic prescriptions). We included videos available from other interventions for communication strategies and DPs and provided links to instructional videos on using the POCCRPT analyser. Workshop participants expressed different views on whether the website should be offered as online training to be completed sequentially with a certificate of completion, or if it should be used flexibly-with any section/webpage accessible directly (nonsequentially). Following our guiding principles to support choice, autonomy and tailoring, we decided to enable flexible use. This meant users could access webpages directly from the menus; however, we also included links to sequential webpages at the bottom of each page. Professionals also wanted clear instructions on when to use and not use POC-CRPT (e.g. which patients/conditions). This was an important clinical question and so we provided links to existing guidelines and evidence for when to use POC-CRPT. Finally, professionals also discussed that the role of practice champions may need to be incentivised. To help provide an intrinsic incentive, we explained the importance of this role on the website-we were unable and considered it impractical to offer any extrinsic incentives (e.g. financial).

\section{Step 4: Refining intervention materials (think-aloud interviews)}

Methods Think-aloud interviews with health professionals were used to collect detailed feedback to refine the online component of the intervention and resources. Professionals were recruited from those involved in previous stages of the research (e.g. workshops) and through research team networks. Interviews (lasting about an hour) took place remotely or in person. All participants gave informed consent and were reimbursed for their time.

Interviews were conducted by $\mathrm{AJB}, \mathrm{AC}$, and $\mathrm{ED}$ between July and October 2019. Participants were given a link and asked to freely navigate and read the website during the interview. They were asked to read the webpages commenting ('thinking aloud') about the content, design, navigation and any other aspects if they wished to. Interviews were audio-recorded and detailed notes were made during the interviews.

Each participant's suggestions were inserted into a table and then assessed using pre-existing criteria for deciding whether to make modifications and MoSCoW ranking (i.e. Must, Should, Could, Would like to change, or no change) [40]. Changes that were deemed 'Must do' or simple to do were addressed immediately after the interviews; other changes were addressed after every few interviews. We continued the interviews until no major suggestions for changes were made and data saturation was reached.

Results Twenty-two professionals completed thinkaloud interviews (12 GPs, 4 practice nurse prescribers, 2 CCG prescribing advisors, 2 practice pharmacy prescribers, 
Table 4 Summary of feedback from the first set of design workshops and resulting changes

\section{Main comments \& suggestions \\ Main changes to the intervention}

Communication skills - professional workshop:

- Already use communication skills but are open to new ideas for things

- Changed the communication webpage name \& title of the handout for

with about antibiotics); need to highlight what is new; suggestions to call

it 'enhancing your communication skills', 'finding the right words' or 'tips/ ideas for things to say to patients'.

- Provide example phrases but keep short to avoid lengthening the consultation.

- Leaflets should be discussed with patients, not just handed-out.

Communication skills - citizen workshop:

- Provide examples of helpful and unhelpful communication strategies

(e.g. need for acknowledging illness, addressing pain, discussing side

effects of antibiotics)

- Leaflets can be helpful but should not replace the conversation.

POC-CRPT - professional workshop only:

- Need to be clear that tests shouldn't be done in all patients; practices need an agreed protocol for when and how they will use the tests, and complete training in using and interpreting the tests.

- Tests perceived as potentially helpful with 'borderline' patients and to benchmark clinicians' 'gut feeling'.

Delayed prescriptions (DP) - professional workshop:

- Calling them 'back-up' prescriptions preferred as more reassuring than 'delayed'.

- DP can be confusing to patients ('why are you giving a prescription when explaining that antibiotics aren't needed?').

- The 6R model for communicating about DP should be combined with the CHESTSSS communication steps; clinicians are unlikely to explicitly go through a list of 6Rs. Training should be simpler and shorter.

- Post-dating prescriptions can be seen as patronising and lead to patient complaints.

- Need for a consistent approach to DP across prescribers.

Delayed prescriptions (DP) - citizen workshop:

- 'Back-up' preferred to 'delayed', or explanation that the prescription is 'in case'.

- DP perceived as confusing ('why offer it after explaining that antibiotics won't help?'); patients would prefer to re-consult rather than have a DP.

- Need something to help patients remember how/when to use the DP.

- Need clear communication on when antibiotics will work or not, and

on when to use the DP ('if you're getting worse' is too vague).

- The 6R model perceived as long; suggestions to shorten it to a more meaningful acronym (e.g. WAIT).

- Post-dating would be perceived as insulting as suggesting clinician's lack of trust in the patient.

Champions - professional workshop only:

- Champions for antibiotics/AMS are helpful, otherwise focus is lost among other priorities. The champion needs to be someone who is already part of practice team (e.g. not someone from CCG).

- Need to involve the whole practice team and agree a consistent approach to antibiotics.

- Practice antibiotic champions could lead practice meetings/training.

Other key comments about implementation intervention - professional workshop only:

- Need to help clinicians see how the training will be useful for them and their practice.

- Make the training a part of the existing electronic system/training programme.

- Present information in varied ways to cater for different preferences and learning styles.

- Keep the training/information as brief as possible; use bullet points rather than long sentences or paragraphs.

- Have summary sheets (up to one side of A4) to briefly summarise/ highlight key messages.

- Additional training to be offered by a provider/trainer.

- Suggestions of when tests can help included on webpage.

- Used 'back-up/delayed' wording throughout website/resources.

- Clarified the suggested use of DP with prognostic uncertainty rather than when patients don't need antibiotics to avoid mixed messages; examples phrases provided to avoid confusion.

- Removed 6 Rs and replaced with acronym WAIT to refer to elements of communication about DP.

- DP linked to communication strategies (CHESTSSS) on website.

- Examples of helpful and unhelpful explanations of DP added to website.

- Focus on practice champions rather than CCG champions.

- Practice meetings to involve discussions and promote consensus on practice-wide approaches.

- Refer to benefits of using the strategies promoted to optimise antibiotics on the website home page.

- Made the text more concise; used more bullet points, boxes, and tables.

- Provided two handouts for clinicians to summarise communication and DP. 
Table 5 Main changes to the intervention following the second set of design workshops

\begin{tabular}{|c|c|}
\hline Website section & Main changes made in result of the suggestions in the second workshop \\
\hline Overall website & $\begin{array}{l}\text { - Replaced references to 'GPs' with 'prescribers'. } \\
\text { - Added a Resources webpage with a list of all downloadable leaflets and resources, links to additional external resources (e.g. } \\
\text { TARGET toolkit) and research papers/evidence. } \\
\text { - Reduced the number of separate webpages for each section and moved non-essential text into expandable boxes for use if } \\
\text { people want more details. }\end{array}$ \\
\hline Home webpage & $\begin{array}{l}\text { - Main focus on the three AMS strategies, with short explanations what they are and direct links to these sections. } \\
\text { - Presented the three AMS strategies in a purposeful order; communication skills and leaflets, POC-CRPT and DP. }\end{array}$ \\
\hline $\begin{array}{l}\text { Section on communication skills and } \\
\text { leaflets }\end{array}$ & $\begin{array}{l}\text { - Added videos with a GP giving examples of communication strategies (helpful phrases). } \\
\text { - Clarified that despite focus on acute infections, these strategies can be applicable to other types of consultations. } \\
\text { - Shortened the text; highlighted examples found particularly helpful and novel by workshops participants. } \\
\text { - Added sections on 'benefits of leaflets' and 'how to use leaflets to engage patients'. }\end{array}$ \\
\hline Section on POC-CRPT & $\begin{array}{l}\text { - Addressed the concern that POC-CRPT may increase demand and appointments for tests. } \\
\text { - Clarified when to use and not use POC-CRPT. }\end{array}$ \\
\hline Section on DP & $\begin{array}{l}\text { - Addressed the concern that patients use DPs immediately by referring to trial evidence that shows that most }(2 / 3) \text { patients } \\
\text { don't end up using DP. } \\
\text { - Clarified that DP should not be offered if the GP doesn't think antibiotics are clinically needed, but rather instead of } \\
\text { immediate antibiotics. } \\
\text { - Highlighted the potential benefits of DP (e.g. reducing re-consultations or 'doctor-shopping'). }\end{array}$ \\
\hline $\begin{array}{l}\text { Section on Implementation Support and } \\
\text { Champions }\end{array}$ & $\begin{array}{l}\text { - Explained who is meant by a practice Antibiotic Champion. } \\
\text { - Explained why champions are important. (Suggestion to offer financial incentives was unaddressed as unfeasible.) } \\
\text { - Suggested that champions may identify another professional to help with some activities. }\end{array}$ \\
\hline
\end{tabular}

1 pharmacy prescriber, and 1 advanced paramedic practitioner). The interviews lasted 37-73 (mean 56) minutes. Thirteen were conducted by telephone, six face-to-face, and three by Skype.

Table 6 presents examples of suggestions and how we addressed them. The main changes were made to the layout of webpages, improved navigation, further condensing and reducing text and providing links directly to guidelines and evidence. The most mixed views related to whom the website would be useful (some found it useful, others suggested it would be useful to less experienced prescribers), preferences and views on each of the three strategies, perceived lack of incentive to read the website, and whether it should be formatted like an instructional course with a certificate of completion. The most positive views related to content are as follows: examples of communication strategies and what not to say when explaining DPs (to avoid mixed messages to patients), information on typical duration of common infections, instructions on using the POC-CRPT equipment and interpreting test results and suggestions for champions to address common questions and concerns. Participants also liked references to guidelines and evidence, and institutional logos and endorsements were perceived as adding credibility. After many changes, in later interviews, they also reported the text as clear, concise and 'punchy'.

\section{Antibiotic Optimisation implementation intervention}

Here we describe the final version of the implementation intervention. Behaviour change techniques [41] that were included in the intervention are reported in Supplementary File 2. Further website details are in Supplementary File 3. The completed Template for Intervention Description and Replication (TIDieR) checklist [42] is in Supplementary File 4.

The implementation intervention has four components (Fig. 3), described below. As depicted in the logic models, the intervention targeted changes at practicelevel and individual-level.

First, practices are asked to identify a practice-based antibiotic champion to lead implementation of the AMS strategies in the practice and to support and encourage other clinicians. The antibiotic champion could be a prescribing lead, GP or nurse practitioner interested in infections and antibiotic optimisation, or any other clinician responsible for AMS in the practice. The role could also be shared by two professionals.

Second, practices are asked to organise at least one practice meeting focused on antibiotic optimisation and the AMS strategies. We suggest meeting(s) is/are led by the antibiotic champion(s). The first meeting aims to raise awareness and motivation to optimise antibiotics: it should focus on introducing the three AMS strategies, the antibiotic optimisation website and associated resources and facilitate discussions and agreement on when and how the strategies are implemented in the practice. Subsequent meetings (every 2-3 months) are suggested to help remind prescribers about the strategies and resources, review implementation and inform new or locum staff about them.

Component $3 \mathrm{a}$, targeted at practice-level change, is the 'Implementation Support' section on the Antibiotic Optimisation website. This introduces the champion role, suggests actions for champions to promote implementation of the AMS strategies and helps address common questions and concerns. It includes guidance to help champions lead introductory and subsequent meetings 
Table 6 Summary of feedback from think-aloud interviews and resulting changes

\begin{tabular}{|c|c|c|}
\hline Website section & $\begin{array}{l}\text { Example suggestions from think-aloud interviews with health } \\
\text { professionals }\end{array}$ & How they were addressed \\
\hline Home page & $\begin{array}{l}\text { - The website was perceived as unattractive without pictures. } \\
\text { - Unclear why these three AMS strategies are promoted. } \\
\text { - Unclear logo. More 'branding' would seem helpful. }\end{array}$ & $\begin{array}{l}\triangleright \text { Added pictures for each AMS strategy. } \\
\triangleright \text { Clarified reasons for promoting the three } \\
\text { strategies. } \\
\triangleright \text { Unchanged as participants held different views } \\
\text { and was not considered a priority. }\end{array}$ \\
\hline $\begin{array}{l}\text { Section on } \\
\text { communication strategies }\end{array}$ & $\begin{array}{l}\text { - Example phrases and mock conversations liked. } \\
\text { - Perceived difficulty with using leaflets with patients where English } \\
\text { isn't their first language; unclear how they could access leaflets in } \\
\text { other languages from the website. } \\
\text { - Some disliked the mnemonic CHESTSSS, seen as hard to remember. } \\
\text { - Too many webpages to go through to access the leaflets. }\end{array}$ & $\begin{array}{l}>\text { Added more example phrases. } \\
>\text { Highlighted availability of leaflets in other } \\
\text { languages and provided a link to them. } \\
>\text { CHESTSSS retained as covering all key } \\
\text { elements. } \\
>\text { Moved all information on leaflets to one } \\
\text { webpage. }\end{array}$ \\
\hline Section on POC-CRPT & $\begin{array}{l}\text { - References to NICE guideline should be highlighted. } \\
\text { - Would like more information on using and interpreting results for } \\
\text { different conditions. } \\
\text { - Add information about manufacturer's training and quality control } \\
\text { tests. } \\
\text { - Questioned if the website/project was funded by CRP test } \\
\text { producers. } \\
\text { - Would like a template or Standard Operating Procedures (SOP) for } \\
\text { using POC-CRPT in practices. }\end{array}$ & $\begin{array}{l}>\text { NICE guidelines and trial evidence highlighted. } \\
>\text { No evidence for different conditions (other } \\
\text { than respiratory infections) so no change. } \\
>\text { Added details on training and quality control. } \\
>\text { Clarified sources of funding. } \\
>\text { No template/SOP provided; suggested } \\
\text { questions to agree on practice approach in } \\
\text { meeting slides. }\end{array}$ \\
\hline Section on DP & $\begin{array}{l}\text { - Concerned about 'red flags' and need for reconsultation or urgent } \\
\text { care. } \\
\text { - Highlight the information on typical duration of common } \\
\text { infections. } \\
\text { - Some confusion about the different names for DP used. }\end{array}$ & $\begin{array}{l}\triangleright \text { Added information on red flags (e.g. sepsis). } \\
\triangleright \text { Added a specific table on typical duration of } \\
\text { infections. } \\
>\text { 'Back-up/delayed' retained as different people } \\
\text { prefer/use different names. }\end{array}$ \\
\hline $\begin{array}{l}\text { Section on } \\
\text { Implementation Support } \\
\text { and Champions }\end{array}$ & $\begin{array}{l}\text { - More focus on addressing concerns and suggested actions for } \\
\text { champions, rather than reasons for promoting AMS. } \\
\text { - Practice meeting slides need to be shorter (for } 5-10-\text { min meetings). } \\
\text { - Unclear who the resources for antibiotic champion webpage/link is } \\
\text { for. } \\
\text { - Information seemed targeted at those who already are champions } \\
\text { and not encouraging people to become one. }\end{array}$ & $\begin{array}{l}\triangleright \text { Shortened the text on reasons and benefits, } \\
\text { and expanded actions for champions. } \\
\triangleright \text { Shortened slides and divided into multiple } \\
\text { sets. } \\
\triangleright \text { Called the webpage 'implementation support'. } \\
\triangleright \text { Edited text to clarify the information is for } \\
\text { everyone promoting prudent prescribing. }\end{array}$ \\
\hline
\end{tabular}

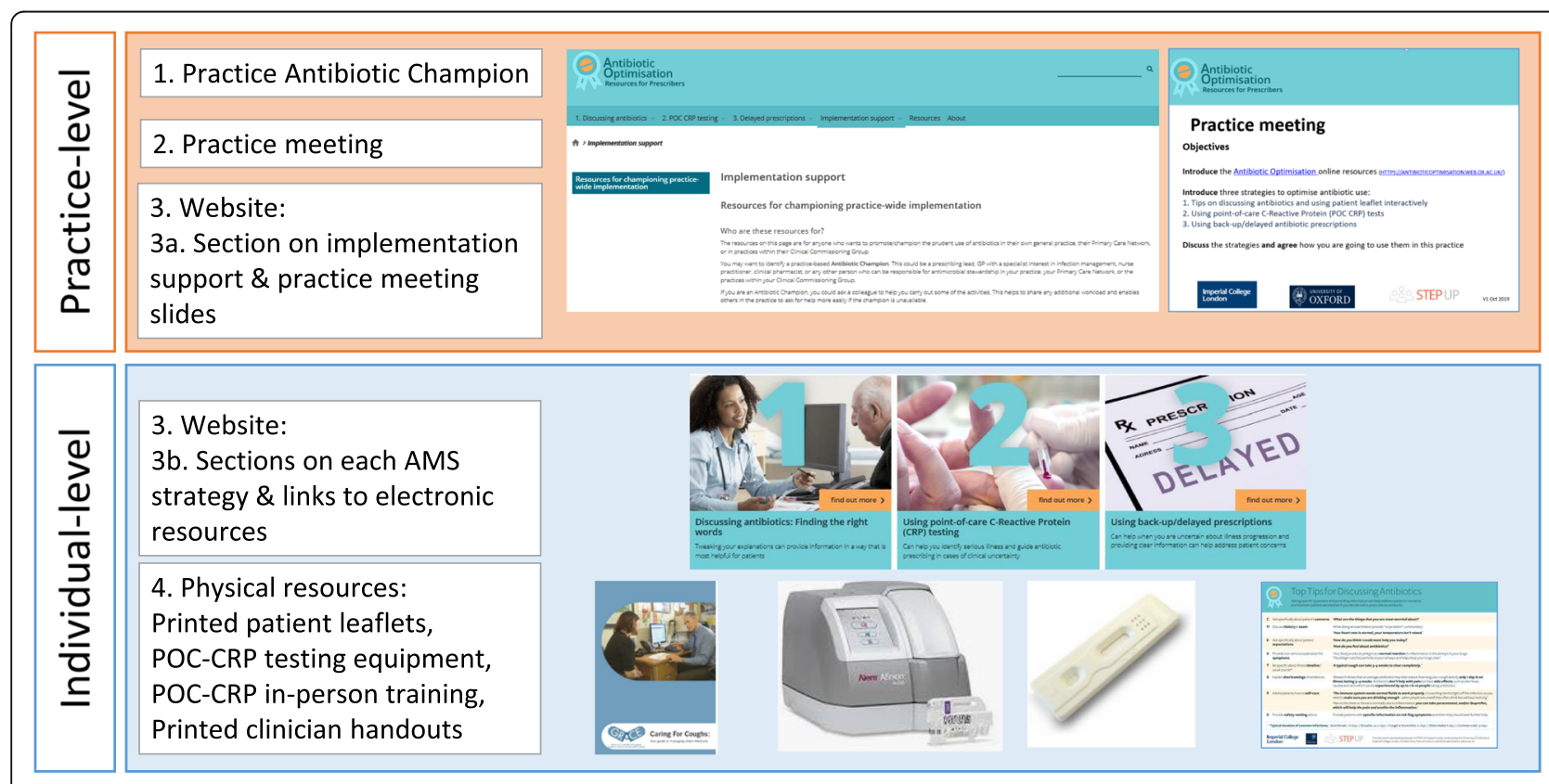

Fig. 3 Components of the Antibiotic Optimisation implementation intervention 
and four sets of PowerPoint meeting slides designed to take 5-10 min to go through-one set providing an overview of the resources and strategies and one set each for the three strategies.

Component $3 \mathrm{~b}$, targeted at individual clinicians, are three AMS strategies (communication strategies and patient leaflets, POC-CRPT, DPs) sections on the Antibiotic Optimisation website. Each section includes evidence-based instructions and rationale on how and why to use the strategies, examples, evidence and guidelines, and videos or quotes from clinicians describing how and why they use the strategies. There are also links for electronic patient leaflets and handouts for clinicians (i.e. short reminder sheets with top tips for discussing antibiotics, interpreting POC-CRPT results, recording POC-CRPT results as part of training and discussing and coding DPs).

The Antibiotic Optimisation website is a key component of the intervention. It is primarily targeted at prescribers, but can be used by any professional involved in implementing the three AMS strategies (e.g. practice nurses doing POC-CRPT). It can be used flexibly, e.g. non-sequentially as any section and page can be accessed directly or sequentially by links at the bottom of each page. All professionals have access to all parts of the website. Our think-aloud interviews indicated that reading the whole website takes up to $1 \mathrm{~h}$. Supplementary File 3 reports the content of each section.

The fourth component provides resources to enable use of the AMS strategies. These include printed versions of patient leaflets/booklets and clinician handouts, and two types of POC-CRPT equipment. In our focus groups, time was reported to be a critical factor and participants considered one of the three tests discussed to be too long for general practice consultations so we excluded it from the intervention. The POC-CRPT website section directs users to providers of the POC-CRPT equipment who offer in-person training. We also suggest a training task: all prescribers use the POC-CRPT on the first 10 patients with acute cough and record the results on a handout.

The next step of this study involved implementing the implementation intervention in high-prescribing general practices in England and a mixed-methods evaluation. Following this, we are in the process of incorporating the resources into existing, publicly available AMS resources. Until made publicly available, the website and resources can be provided from the authors on reasonable request. There is no specific number of times or period over which the intervention should be delivered; rather, we envisage that health professionals engage with it in ways that suit them and when they want additional support with implementing the three AMS strategies.

\section{Discussion}

In this paper, we describe the process of developing the Antibiotic Optimisation intervention to promote and support the uptake and implementation of three evidence-based AMS strategies in high-prescribing general practices. This was an iterative process of intervention planning, design, development and refinement, in which we combined evidence, theoretical modelling and qualitative research with target users and stakeholders.

The Antibiotic Optimisation implementation intervention was targeted at health professionals in general practice. While we focused on the context of general practice and involved primary care stakeholders, the final intervention has some similarities with the Antibiotic Review Kit (ARK) intervention to safely review and reduce antibiotic prescriptions in hospitals [33]. Both have components targeted at individuals (e.g. online tool/website, patient leaflets) and at teams - 'implementation teams' in ARK and practice teams in our intervention (e.g. implementation guidance/website, champions). Implementation requires both individual and organisational change, so the targets for, and processes in, implementation interventions are more complex and multi-level than interventions focussed on individuals only. Other studies also evaluated the implementation of intervention components similar to our implementation intervention (e.g. online training, champions, outreach visits, leaflets) [4345]. However, unlike in these studies, we distinguished AMS strategies (e.g. POC-CRPT, DPs) that aim to influence antibiotic prescribing decisions from implementation strategies (e.g. champions, website) that aim to influence the uptake and implementation of the AMS strategies in practices. This is illustrated by our two logic models where we specified the intended 'mechanisms of action' of different types of intervention components.

Digital components (websites, e-learning modules) are important in our and many other interventions and are commonly used to provide training and education for clinicians. A systematic review of eight trials in primary care found that digital education on antibiotic management was more effective in improving knowledge and likely more cost-effective than traditional education [46]. Online AMS training for all patient-facing staff was also one of the highest-ranked AMS interventions by primary care stakeholders in previous research [47].

Nevertheless, engagement with digital interventions remains challenging. Health professionals in the ARK study were sceptical about digital education due to high workloads and limited time (the 30-min ARK e-module was shortened to $10 \mathrm{~min}$ ) [33]. Similarly, we found a main barrier to optimising antibiotics and engaging with AMS strategies in general practice was limited time. Thus, we revised the website, handouts and practice meeting slides until they were as concise as possible, but 
it remains uncertain how acceptable the time required to engage with them is. We also decided not to offer the 10-min POC-CRPT as it was deemed too timeconsuming by clinicians. In our focus groups [26], we found that an important barrier to using POC-CRPT and DPs was ambiguity about evidence and when, and how, to use the strategies; and professionals in our workshops and think-aloud interviews asked for evidence and clear guidelines on using these strategies. Consequently, we needed to strike a balance between making the intervention short and not losing important content, and between providing evidence and guidance while allowing flexibility and autonomy.

We have previously identified the importance of national and local champions as facilitators to engagement and implementation in our qualitative research with CCG and general practice professionals [7] and with primary care stakeholders [47]. Growing literature on champions and leaders in primary care supports their important role in facilitating implementation of AMS strategies [43, 48] and other initiatives (e.g. [49, 50]). However, a qualitative study with Norwegian GPs showed a need for leadership training and tensions between GPs' clinical and leadership roles [51]. We initially explored involving CCG prescribing advisors as champions but professionals in our workshops suggested practice-based champions more suited to help implement the strategies within practice contexts and support colleagues. However, they also suggested providing incentives (e.g. paying for their time), which was unfeasible in our study and complex in the real-world context. Finally, as we previously found [7], in-person communication in practices was preferred (e.g. practice meetings), although challenging with time constraints. Wider, national implementation of interventions often means that digital, remote delivery is more feasible without the in-person components (helping to lower cost and time requirements). For example, the 'STAR' communication training initially involved digital training and a practice-based seminar, but it is currently available online only $[18,19]$. The 'TARGET' ('Treat Antibiotics Responsibly, Guidance, Education, Tools') training initially also had digital and in-person elements, and its national implementation involves training trainers to continue delivering in-person training $[52,53]$. Our intervention promotes practice meetings led by practice-based professionals, making it potentially more flexible and sustainable in real-world settings, enabling ownership of the initiatives and implementation, and consistent practice between professionals.

A recent framework for planning, conducting and disseminating AMR intervention research has called for research to be more responsive to stakeholder needs and for interventions to be better designed, including consideration of behavioural determinants, theory and logicmodels [54]. Different approaches and tools have been established and used to develop health-related behaviour change interventions [55]; e.g. Medical Research Council guidance [56], Intervention Mapping [57], the Behaviour Change Wheel [58] and the Person-Based Approach (PBA) [28-30]. These approaches can be also used to develop interventions to support implementation. We drew on the PBA for its suitability for designing interventions with digital components and focus on stakeholder engagement and co-design with target users; thus, helping increase the likelihood of the intervention being relevant, acceptable and feasible.

However, we found challenges with the PBA. For example, it encourages a digital delivery early in the intervention development process, which may not always be the most optimal delivery format. Moreover, in complex behaviours, such as implementation of (also complex) AMS strategies, it is challenging to identify the most important influences on behaviour and determinants of change. For example, we identified over 41 types of influences on antibiotic prescribing from qualitative research. It was unclear which were most important and what other unidentified influences (e.g. subconscious) may also be important. We tried to address influences that were commonly reported and that resonated most with stakeholders and the study team. This resulted in trying to address many influences but to different extents (e.g. some only by including brief information on the website). Finally, it is unclear how the many approaches to behaviour change intervention development [55] may be incorporated with the many implementation frameworks and models which exist [59]. In our research, we were aware of the concepts included in the implementation frameworks but did not use them explicitly; an implementation framework will be used to guide the evaluation in the implementation study.

\section{Strengths and limitations}

We followed a pre-defined, systematic process to developing the intervention, identifying and addressing views and experiences of target users, while also incorporating evidence- and theory-based elements. We engaged a relatively large and diverse number of relevant stakeholders. We also engaged citizens (members of the public) to better understand and incorporate patient perspectives. In the qualitative sub-studies, we reached data saturation. A strength was also our multidisciplinary team of experienced researchers and clinicians, who led and advised on the intervention development. We followed guidance for reporting interventions [42] and intervention development studies [60] (checklists are in Supplementary Files 4 and 5).

Limitations of the study, and thus potentially of the developed intervention, remain. We acknowledge that there are other effective AMS strategies that could be 
considered for implementation (e.g. clinical decision support tools) and that our focus on the three evidence-based AMS strategies was to some extent influenced by the expertise and interests of the research team and the scope of our study. The interviewers were involved in intervention development so there was potential for socially desirable answers in the workshops and think-aloud interviews. However, our data show that participants expressed critical comments. Professionals attending the workshops were likely to be more interested in AMS and optimising antibiotics so their views and experiences might have differed from professionals less engaged in AMS. However, we also incorporated findings and suggestions from focus groups conducted in high-prescribing practices. Some professionals involved had previous experience of implementing/using the AMS strategies and could share their experiences, whereas others had not used some of the AMS strategies (e.g. POC-CRPT) which meant that they approached the strategies with fresh eyes. We conducted think-aloud interviews only and did not conduct interviews after giving people time to use the website/resources on their own (as suggested by Bradbury et al. [61]); these will be part of the mixed-methods evaluation in the next stage. Not all suggestions were feasible or practical to address and there are wider contextual influences that affect high antibiotic prescribing [62], which are beyond the target for one practice-based intervention. In our qualitative data collection, we relied on participants' reports of views and experiences. These may differ from actual behaviour and do not uncover subconscious influences. Thus, other methods, such as observations, may be also needed (e.g. in future studies). Finally, it is as yet unclear how applicable and fitting the intervention has been during, and will be after, the COVID-19 pandemic which has, at least temporarily, transformed how general practices work.

\section{Conclusions}

In this article, we report the development of an implementation intervention which followed a systematic, user- and stakeholder-focussed process. We describe the multicomponent 'Antibiotic Optimisation' intervention that aims to promote the implementation of evidencebased AMS strategies in general practices. Our intervention targets individual- and practice-level behaviour change processes. In the next stage of our research, the intervention has been piloted and evaluated in an implementation study. With increasing numbers of AMS strategies and interventions and growing trial-based evidence of effectiveness, it is now critical to work towards bridging the gap between evidence and practice and improve implementation of evidence-based strategies, particularly in high-prescribing practices that need to further optimise antibiotic prescribing.

\section{Abbreviations}

AMR: Antimicrobial resistance; AMS: Antimicrobial stewardship; CCG: Clinical Commissioning Group; DPs: Delayed/back-up prescriptions; GP: General practitioner; PBA: Person-Based Approach; POC-CRPT: Point-of-care C-reactive protein testing

\section{Supplementary Information}

The online version contains supplementary material available at https://doi. org/10.1186/s43058-021-00209-7.

Supplementary File 1. Complete table of influences on antibiotic prescribing and optimisation. Supplementary File 2. Theoretical Domains Framework constructs and Behaviour Change Techniques. Supplementary File 3. Details of the Antibiotic Optimisation implementation intervention. Supplementary File 4. The TIDieR checklist. Supplementary File 5. The GUIDED checklist.

\section{Acknowledgements}

We thank the health professionals and citizens for participating in the study. This paper is part of the work of the STEP-UP study team (https://www. expmedndm.ox.ac.uk/step-up/step-up) comprising Philip E. Anyanwu, Aleksandra J. Borek, Nicole Bright, James Buchanan, Christopher C. Butler, Anne Campbell, Ceire Costelloe, Benedict Hayhoe, Alison Holmes, Susan Hopkins, Azeem Majeed, Monsey Mcleod, Michael Moore, Liz Morrell, Koen B. Pouwels, Julie V. Robotham, Laurence S. J. Roope, Sarah Tonkin-Crine, Ann Sarah Walker, Sarah Wordsworth, Carla Wright, Sara Yadav and Anna Zalevski.

\section{Authors' contributions}

AJB - contributed to the study design and all stages of the intervention development, facilitated the participant recruitment and data collection, analysed the data and drafted the manuscript. AC — contributed to the study design and all stages of the intervention development, facilitated the participant recruitment and data collection, analysed the data and revised the manuscript. ED - contributed to the data collection and analysis. CCB, $\mathrm{MM}, \mathrm{AH}, \mathrm{ASW}$-obtained the funding, contributed to the study design and intervention development and provided comments on the manuscript. MMc-obtained the funding, contributed to the study design and all stages of the intervention development, facilitated participant recruitment and data collection, analysed the data and revised the manuscript. STC-obtained the funding, contributed to the study design and all stages of the intervention development, facilitated the participant recruitment and data collection, analysed the data and revised the manuscript. The authors read and approved the final manuscript.

\section{Funding}

The study was funded by the Economic and Social Research Council (ESRC) through the Antimicrobial Resistance Cross Council Initiative supported by the seven research councils in partnership with other funders (grant reference: ES/P008232/1) and supported by the National Institute for Health Research (NIHR) Health Protection Research Unit (HPRU) in Healthcare Associated Infections and Antimicrobial Resistance at the University of Oxford and Imperial College London in partnership with Public Health England, the NIHR Oxford Biomedical Research Centre and the NIHR Imperial Patient Safety Translational Research Centre (PSTRC-2016-004). ASW, AH and CCB are NIHR Senior Investigators. This study was additionally supported by a small grant from the NIHR Imperial Biomedical Research Centre managed by the Patient Experience Research Centre. The support of the funders is gratefully acknowledged.

The funding bodies played no role in the design of the study and collection, analysis, and interpretation of data and in writing the manuscript. The views expressed are those of the authors and not necessarily those of the NHS, the $\mathrm{NIHR}$, the Department of Health and Social Care or Public Health England. Manufacturers of point-of-care CRP tests had no financial relationship with this study or research team, and no influence on the study design, conduct or interpretation of results.

\section{Availability of data and materials}

The datasets analysed during this study are available from the corresponding author on reasonable request. 


\section{Declarations}

\section{Ethics approval and consent to participate}

The University of Oxford research ethics committee (ref. R59812) and NHS Health Research Authority (ref. 19/HRA/0434) approved the study. All participants provided written or verbal informed consent for participation in the study.

\section{Consent for publication}

Not applicable.

\section{Competing interests}

The authors declare that they have no competing interests.

\section{Author details}

${ }^{1}$ Nuffield Department of Primary Care Health Sciences, University of Oxford, Radcliffe Observatory Quarter, Woodstock Road, Oxford OX2 6GG, UK. ${ }^{2}$ National Institute for Health Research (NIHR) Health Protection Research Unit in Healthcare Associated Infections and Antimicrobial Resistance, Imperial College London, London, UK. ${ }^{3}$ Primary Care Population Sciences and Medical Education, Faculty of Medicine, University of Southampton, Southampton, UK. ${ }^{4} \mathrm{NIHR}$ Health Protection Research Unit in Healthcare Associated Infections and Antimicrobial Resistance, University of Oxford, Oxford, UK. ${ }^{5}$ NIHR Oxford Biomedical Research Centre, Oxford, UK. ${ }^{6}$ Nuffield Department of Medicine, University of Oxford, Oxford, UK. ${ }^{7}$ Centre for Medication Safety and Service Quality, Pharmacy Department, Imperial College Healthcare NHS Trust, London, UK. ${ }^{8} \mathrm{NIHR}$ Imperial Patient Safety Translational Research Centre, Imperial College London, London, UK.

Received: 24 May 2021 Accepted: 30 August 2021

Published online: 15 September 2021

\section{References}

1. Public Health England. English surveillance programme for antimicrobial utilisation and resistance (ESPAUR) Report 2018 - 2019. London: Public Health England; 2019. https://webarchive.nationalarchives.gov.uk/202 00806045257/https://www.gov.uk/government/publications/english-surveilla nce-programme-antimicrobial-utilisation-and-resistance-espaur-report. Accessed 5 May 2021.

2. Tonkin-Crine SK, Tan PS, van Hecke O, Wang K, Roberts NW, McCullough A, et al. Clinician-targeted interventions to influence antibiotic prescribing behaviour for acute respiratory infections in primary care: an overview of systematic reviews. Cochrane Database Syst Rev. 2017;9:CD012252.

3. McDonagh MS, Peterson K, Winthrop K, Cantor A, Lazur BH, Buckley DI. Interventions to reduce inappropriate prescribing of antibiotics for acute respiratory tract infections: summary and update of a systematic review. J Int Med Res. 2018;46(8):3337-57. https://doi.org/10.1177/0300060518782519.

4. Köchling A, Löffler C, Reinsch S, Hornung A, Böhmer F, Altiner A, et al. Reduction of antibiotic prescriptions for acute respiratory tract infections in primary care: a systematic review. Implement Sci. 2018;13(1):47. https://doi. org/10.1186/s13012-018-0732-y.

5. NHS England. Quality Premium. https://www.england.nhs.uk/ccg-out-tool/ qual-prem. Accessed 5 May 2021

6. PrescQIPP. https://www. prescqipp.info. Accessed 5 May 2021

7. Borek AJ, Anthierens S, Allison R, McNulty CAM, Lecky DM, Costelloe C, et al. How did a Quality Premium financial incentive influence antibiotic prescribing in primary care? Views of Clinical Commissioning Group and general practice professionals. J Antimicrob Chemother. 2020;75(9):2681-8. https://doi.org/10.1093/jac/dkaa224.

8. Allison R, Lecky DM, Beech E, Costelloe C, Ashiru-Oredope D, Owens R, et al What antimicrobial stewardship strategies do NHS commissioning organizations implement in primary care in England? JAC Antimicrob Resist. 2020;2(2):1-10. https://doi.org/10.1093/jacamr/dlaa020.

9. Spurling GK, Mar CBD, Dooley L, Foxlee R, Farley R. Delayed antibiotic prescriptions for respiratory infections. Cochrane Database Syst Rev. 2017; 9(7). https://doi.org/10.1002/14651858.CD004417.pub5.

10. Little P, Stuart B, Francis N, Douglas E, Tonkin-Crine S, Anthierens S, et al. Effects of internet-based training on antibiotic prescribing rates for acute respiratory-tract infections: a multinational, cluster, randomised, factorial, controlled trial. Lancet. 2013;382(9899):1175-82. https://doi.org/10.1016/S014 0-6736(13)60994-0.
11. Little P, Stuart B, Francis N, Douglas E, Tonkin-Crine S, Anthierens S, et al Antibiotic prescribing for acute respiratory tract infections 12 months after communication and CRP training: a randomized trial. Ann Fam Med. 2019; 17(2):125-32. https://doi.org/10.1370/afm.2356.

12. Yardley L, Douglas E, Anthierens S, Tonkin-Crine S, O'Reilly G, Stuart B, et al. Evaluation of a web-based intervention to reduce antibiotic prescribing for LRTI in six European countries: quantitative process analysis of the GRACE/ INTRO randomised controlled trial. Implement Sci. 2013;8(1):134. https://doi. org/10.1186/1748-5908-8-134.

13. Francis NA, Butler CC, Hood K, Simpson S, Wood F, Nuttall J. Effect of using an interactive booklet about childhood respiratory tract infections in primary care consultations on reconsulting and antibiotic prescribing: a cluster randomised controlled trial. BMJ. 2009;339:b2885. https://doi.org/1 $0.1136 /$ bmj.b2885

14. Gulliford MC, Prevost AT, Charlton J, Juszczyk D, Soames J, McDermott L, et al. Effectiveness and safety of electronically delivered prescribing feedback and decision support on antibiotic use for respiratory illness in primary care: REDUCE cluster randomised trial. BMJ. 2019;364:|236. https:// doi.org/10.1136/bmj.I236.

15. Little P, Moore M, Kelly J, Williamson I, Leydon G, McDermott L, et al. Delayed antibiotic prescribing strategies for respiratory tract infections in primary care: pragmatic, factorial, randomised controlled trial. BMJ. 2014;348: g1606. https://doi.org/10.1136/bmj.g1606.

16. Little P, Stuart B, Hobbs FDR, Butler CC, Hay AD, Delaney B, et al. Antibiotic prescription strategies for acute sore throat: a prospective observational cohort study. Lancet Infect Dis. 2014;14(3):213-9. https://doi.org/10.1016/S14 73-3099(13)70294-9.

17. Little P, Stuart B, Smith S, Thompson MJ, Knox K, van den Bruel A, et al. Antibiotic prescription strategies and adverse outcome for uncomplicated lower respiratory tract infections: prospective cough complication cohort (3C) study. BMJ. 2017;357:j2148. https://doi.org/10.1136/bmj.j2148.

18. Butler CC, Simpson SA, Dunstan F, Rollnick S, Cohen D, Gillespie D, et al. Effectiveness of multifaceted educational programme to reduce antibiotic dispensing in primary care: practice based randomised controlled trial. BMJ. 2012;344:d8173. https://doi.org/10.1136/bmj.d8173.

19. STAR: Stemming the Tide of Antibiotic Resistance. https://www.healthca recpd.com/course/star-stemming-the-tide-of-antibiotic-resistance. Accessed 5 May 2021

20. When should I worry? http://www.whenshouldiworry.com. Accessed 5 May 2021

21. Johnson M, Cross L, Sandison N, Stevenson J, Monks T, Moore M. Funding and policy incentives to encourage implementation of point-of-care Creactive protein testing for lower respiratory tract infection in NHS primary care: a mixed-methods evaluation. BMJ Open. 2018;8(10):e024558. https:// doi.org/10.1136/bmjopen-2018-024558.

22. Eley CV, Sharma A, Lecky DM, Lee H, McNulty CAM. Qualitative study to explore the views of general practice staff on the use of point-of-care $C$ reactive protein testing for the management of lower respiratory tract infections in routine general practice in England. BMJ Open. 2018;8(10): e023925. https://doi.org/10.1136/bmjopen-2018-023925.

23. Huddy JR, Ni MZ, Barlow J, Majeed A, Hanna GB. Point-of-care C reactive protein for the diagnosis of lower respiratory tract infection in NHS primary care: a qualitative study of barriers and facilitators to adoption. BMJ Open. 2016;6(3):e009959. https://doi.org/10.1136/bmjopen-2015-009959.

24. Ryves R, Eyles C, Moore M, McDermott L, Little P, Leydon GM. Understanding the delayed prescribing of antibiotics for respiratory tract infection in primary care: a qualitative analysis. BMJ Open. 2016;6(11): e011882. https://doi.org/10.1136/bmjopen-2016-011882.

25. Peters S, Rowbotham S, Chisholm A, Wearden A, Moschogianis S, Cordingley $L$, et al. Managing self-limiting respiratory tract infections: a qualitative study of the usefulness of the delayed prescribing strategy. $\mathrm{Br}$ J Gen Pract. 2011;61(590):e579-89. https://doi.org/10.3399/bjgp11X593866.

26. Borek AJ, Campbell A, Dent E, Butler CC, Holmes A, Moore M, et al. Implementing interventions to reduce antibiotic use: a qualitative study in high-prescribing practices. BMC Fam Pract. 2021;22(1):25. https://doi.org/1 0.1186/s12875-021-01371-6.

27. STEP-UP study: improving the uptake and sustainability of effective interventions to promote prudent antibiotic use in primary care. https:// www.expmedndm.ox.ac.uk/step-up. Accessed 5 May 2021.

28. Yardley L, Ainsworth B, Arden-Close E, Muller I. The person-based approach to enhancing the acceptability and feasibility of interventions. Pilot Feasibility Stud. 2015;1(1):37. https://doi.org/10.1186/s40814-015-0033-z. 
29. Yardley L, Morrison L, Bradbury K, Muller I. The person-based approach to intervention development: application to digital health-related behavior change interventions. J Med Internet Res. 2015;17(1):e30. https://doi.org/1 0.2196/jmir.4055

30. Morrison L, Muller I, Yardley L, Bradbury K. The person-based approach to planning, optimising, evaluating and implementing behavioural health interventions. Eur Health Psychol. 2018;20(3):464.

31. The Person-Based Approach. https://www.personbasedapproach.org. Accessed 5 May 2021.

32. Anthierens S, Tonkin-Crine S, Douglas E, Fernandez-Vandellos P, Krawczyk J, Llor C, et al. General practitioners' views on the acceptability and applicability of a web-based intervention to reduce antibiotic prescribing for acute cough in multiple European countries: a qualitative study prior to a randomised trial. BMC Fam Pract. 2012;13(1):101. https://doi.org/10.11 86/1471-2296-13-101.

33. Santillo M, Sivyer K, Krusche A, Mowbray F, Jones N, Peto TEA, et al. Intervention planning for Antibiotic Review Kit (ARK): a digital and behavioural intervention to safely review and reduce antibiotic prescriptions in acute and general medicine. J Antimicrob Chemother. 2019;74(11):336270. https://doi.org/10.1093/jac/dkz333.

34. Borek AJ, Wanat M, Atkins L, Sallis A, Ashiru-Oredope D, Beech E, et al. Optimising antimicrobial stewardship interventions in English primary care: a behavioural analysis of qualitative and intervention studies. BMJ Open. 2020;10(12):e039284. https://doi.org/10.1136/bmjopen-2020-039284.

35. Borek AJ, Wanat M, Roberts N, Atkins L, Sallis A, Tonkn-Crine S. Exploring the Implementation of Interventions to Reduce Antibiotic Use (ENACT) Study: report. London: Public Health England; 2019.

36. Palin V, Mölter A, Belmonte M, Ashcroft DM, White A, Welfare W, et al. Antibiotic prescribing for common infections in UK general practice: variability and drivers. J Antimicrob Chemother. 2019;74(8):2440-50. https:// doi.org/10.1093/jac/dkz163.

37. Curtis HJ, Walker AJ, Mahtani KR, Goldacre B. Time trends and geographical variation in prescribing of antibiotics in England 1998-2017. J Antimicrob Chemother. 2019;74(1):242-50. https://doi.org/10.1093/jac/dky377.

38. Hope EC, Crump RE, Hollingsworth TD, Smieszek T, Robotham JV, Pouwels $\mathrm{KB}$. Identifying English practices that are high antibiotic prescribers accounting for comorbidities and other legitimate medical reasons for variation. EClinicalMedicine. 2018;6:36-41. https://doi.org/10.1016/j.eclinm.2 018.12.003.

39. Cane J, O'Connor D, Michie S. Validation of the theoretical domains framework for use in behaviour change and implementation research. Implement Sci. 2012;7(1):37. https://doi.org/10.1186/1748-5908-7-37.

40. Bradbury K, Morton K, Band R, van Woezik A, Grist R, McManus RJ, et al. Using the person-based approach to optimise a digital intervention for the management of hypertension. PLoS One. 2018;13(5):e0196868. https://doi. org/10.1371/journal.pone.0196868.

41. Michie S, Richardson M, Johnston M, Abraham C, Francis J, Hardeman W, et al. The behavior change technique taxonomy ( $v 1)$ of 93 hierarchically clustered techniques: building an international consensus for the reporting of behavior change interventions. Ann Behav Med. 2013;46(1):81-95. https:// doi.org/10.1007/s12160-013-9486-6.

42. Hoffmann TC, Glasziou PP, Boutron I, Milne R, Perera R, Moher D, et al. Better reporting of interventions: template for intervention description and replication (TIDieR) checklist and guide. BMJ. 2014;348:g1687.https://doi. org/10.1136/bmj.g1687.

43. Jeffs $L$, Mclsaac W, Zahradnik M, Senthinathan A, Dresser L, McIntyre M, et al. Barriers and facilitators to the uptake of an antimicrobial stewardship program in primary care: a qualitative study. PLoS One. 2020;15(3):e0223822. https://doi.org/10.1371/journal.pone.0223822.

44. Poß-Doering R, Kuehn L, Kamradt M, Glassen K, Fleischhauer T, KaufmannKolle $P$, et al. Converting habits of antibiotic use for respiratory tract infections in German primary care (CHANGE-3) - process evaluation of a complex intervention. BMC Fam Pract. 2020;21(1):274. https://doi.org/10.11 86/s12875-020-01351-2.

45. Petruschke I, Salm F, Kaufmann M, Freytag A, Gensichen J, Behnke M, et al. Evaluation of a multimodal intervention to promote rational antibiotic use in primary care. Antimicrob Resist Infect Control. 2021;10(1):66. https://doi. org/10.1186/s13756-021-00908-9.

46. Kyaw BM, Car LT, van Galen LS, van Agtmael MA, Costelloe CE, Ajuebor O, et al. Health professions digital education on antibiotic management: systematic review and meta-analysis by the digital health education collaboration. J Med Internet Res. 2019;21(9):e14984. https://doi.org/10.21 96/14984.

47. Borek AJ, Wanat M, Sallis A, Ashiru-Oredope D, Atkins L, Beech E, et al. How can national antimicrobial stewardship interventions in primary care be improved? A stakeholder consultation. Antibiotics. 2019;8(4):207. https://doi. org/10.3390/antibiotics8040207.

48. Høye S, Brænd AM, Spehar I. Quality improvement and antimicrobial stewardship in general practice - the role of the municipality chief medical officer. A qualitative study. Scand J Prim Health Care. 2020;38(3):352.

49. Nieuwboer MS, van der Sande R, van der Marck MA, Olde Rikkert MGM, Perry M. Clinical leadership and integrated primary care: a systematic literature review. Eur J Gen Pract. 2019;25(1):7-18. https://doi.org/10.1080/13 814788.2018.1515907.

50. Looman W, Struckmann V, Köppen J, Baltaxe E, Czypionka T, Huic M, et al. Drivers of successful implementation of integrated care for multimorbidity: mechanisms identified in 17 case studies from 8 European countries. Soc Sci Med. 2021;113728:113728. https://doi.org/10.1016/j. socscimed.2021.113728.

51. Spehar I, Sjøvik H, Karevold Kl, Rosvold EO, Frich JC. General practitioners' views on leadership roles and challenges in primary health care: a qualitative study. Scand J Prim Health Care. 2017;35(1):105-10. https://doi. org/10.1080/02813432.2017.1288819.

52. McNulty C, Hawking M, Lecky D, Jones L, Owens R, Charlett A, et al. Effects of primary care antimicrobial stewardship outreach on antibiotic use by general practice staff: pragmatic randomized controlled trial of the TARGET antibiotics workshop. J Antimicrob Chemother. 2018;73(5):1423-32. https:// doi.org/10.1093/jac/dky004.

53. TARGET Antibiotic Toolkit (Treat Antibiotics Responsibly, Guidance, Education, Tools). https://www.rcgp.org.uk/TARGETantibiotics. Accessed 5 May 2021.

54. Rogers Van Katwyk S, Hoffman SJ, Mendelson M, Taljaard M, Grimshaw JM. Strengthening the science of addressing antimicrobial resistance: a framework for planning, conducting and disseminating antimicrobial resistance intervention research. Health Res Pol Syst. 2020;18(1):60.

55. O'Cathain A, Croot L, Sworn K, Duncan E, Rousseau N, Turner K, et al. Taxonomy of approaches to developing interventions to improve health: a systematic methods overview. Pilot Feasibility Stud. 2019;5(1):41. https://doi. org/10.1186/s40814-019-0425-6.

56. Craig P, Dieppe P, Macintyre S, Michie S, Nazareth I, Petticrew M. Developing and evaluating complex interventions: the new guidance. BMJ. 2008:337(sep29 1):a1655.

57. Bartholomew LK, Parcel GS, Kok G, Gottlieb NH, Fernandez ME. Planning health promotion programs: an intervention mapping approach. 4th ed San Francisco: Jossey-Bass; 2016.

58. Michie S, Atkins L, West R. The behaviour change wheel: a guide to designing interventions. London: Silverback Publishing; 2014.

59. Lynch EA, Mudge A, Knowles S, Kitson AL, Hunter SC, Harvey G. "There is nothing so practical as a good theory": a pragmatic guide for selecting theoretical approaches for implementation projects. BMC Health Serv Res. 2018;18(1):857.

60. Duncan E, O'Cathain A, Rousseau N, Croot L, Sworn K, Turner KM, et al. Guidance for reporting intervention development studies in health research (GUIDED): an evidence-based consensus study. BMJ Open. 2020;10(4): e033516. https://doi.org/10.1136/bmjopen-2019-033516.

61. Bradbury K, Watts S, Arden-Close E, Yardley L, Lewith G. Developing digital interventions: a methodological guide. Evid Based Complement Alternat Med. 2014;2014:e561320. https://doi.org/10.1155/2014/561320.

62. Borek AJ, Anthierens S, Allison R, Mcnulty CAM, Anyanwu PE, Costelloe C, et al. Social and contextual influences on antibiotic prescribing and antimicrobial stewardship: a qualitative study with Clinical Commissioning Group and general practice professionals. Antibiotics. 2020;9(12):859. https:// doi.org/10.3390/antibiotics9120859.

\section{Publisher's Note}

Springer Nature remains neutral with regard to jurisdictional claims in published maps and institutional affiliations. 